\title{
Cytoplasmic Inheritance Redux
}

\section{Evan Charney}

Sanford School of Public Policy, Duke University, Durham, NC, USA

E-mail: echar@duke.edu

\section{Contents}

1. Cytoplasmic Inheritance 226

2. Oocyte to Implantation (a Few Basics) 227

3. Maternal Effect Genes 229

4. Epigenetics in the Preimplantation Embryo 232

4.1. Histone Modification 233

4.2. DNA Methylation 234

4.3. Imprinting 236

4.4. Noncoding RNAs 237

4.5. X-chromosome Inactivation 238

5. Cytoplasmic Organelles 238

5.1. Mitochondria 238

5.2. Nucleoli 241

6. Assisted Reproductive Technology 241

6.1. IVF and Epigenetics 243

6.2. The Oviductal Environment 245

$\begin{array}{ll}\text { 7. Conclusions } & 247\end{array}$

$\begin{array}{ll}\text { References } & 248\end{array}$

\section{Abstract}

Since the early twentieth century, inheritance was seen as the inheritance of genes. Concurrent with the acceptance of the genetic theory of inheritance was the rejection of the idea that the cytoplasm of the oocyte could also play a role in inheritance and a corresponding devaluation of embryology as a discipline critical for understanding human development. Development, and variation in development, came to be viewed solely as matters of genetic inheritance and genetic variation. We now know that inheritance is a matter of both genetic and cytoplasmic inheritance. A growing awareness of the centrality of the cytoplasm in explaining both human development and phenotypic variation has been promoted by two contemporaneous developments: the continuing elaboration of the molecular mechanisms of epigenetics and the global rise of artificial reproductive technologies. I review recent developments in the ongoing elaboration of the role of the cytoplasm in human inheritance and development. 


\section{CYTOPLASMIC INHERITANCE}

"Omne vivum ex ovo: Every living thing comes from an egg." As implied in William Harvey's famous statement, the developmental fate of an embryo begins in the oocyte. The initial phase of embryonic development takes place during a period of genetic transcriptional silence until the activation of the embryonic genome. Prior to embryonic genome activation (EGA), the embryo depends entirely upon maternal RNAs, maternal DNA (in mitochondria), maternal organelles, proteins, substrates, and nutrients that have been deposited in the cytoplasm of the ovum during oogenesis. These maternal products control almost every aspect of early embryonic development. Collectively, they constitute an extraordinary maternal "cytoplasmic" inheritance. Variations in this cytoplasmic inheritance-in the "quality" of the oocyte-can have profound developmental consequences for offspring, both short and long terms. But with the exception of mitochondrial DNA (mtDNA), the effects of cytoplasmic inheritance are not due to offspring having inherited maternal (or paternal) genes.

I intentionally use the expression "cytoplasmic inheritance" in place of the more common "maternal inheritance," to place the content of this chapter in historical context: in the early twentieth century, the rejection of the existence of cytoplasmic inheritance had important consequences. It represented the triumph of Mendelian inheritance and supported the development of the Modern Synthesis (Amundson, 2005). The view that inheritance is a matter of genes, not cytoplasm, became something of a dogma in genetics. With the denial of cytoplasmic inheritance came a corresponding diminishment of embryology as a scientific discipline (Gilbert, 1998). This dogma persists to this day, most notably in the approach that characterizes contemporary behavioral genetics: inheritance is a matter of the inheritance of alleles, and variation in alleles - generally, single nucleotide polymorphisms - can provide us with clues to understanding variation in complex phenotypes. Hence, embryology can still be ignored because when it comes to inheritance, what matters are genes and genes alone.

It is beyond any doubt today that cytoplasmic inheritance is a key component of human (biological) inheritance. With the growing awareness of the importance of cytoplasmic inheritance has come the resurrection of embryology. At least two contemporaneous forces have led to a growing awareness of the importance of cytoplasmic inheritance/embryogenesis. First is the continued elaboration of the molecular mechanics of epigenetics 
and the discovery that many of the earliest embryonic processes, those regulated by the maternal cytoplasm, are also epigenetic processes. Second is the global rise of artificial reproductive technologies (ARTs) as a means of conception. Current birth rates of ART-conceived children in a number of developed countries now range from $1 \%$ to $3 \%$ of all births. Concern about reports of increased risk of negative developmental outcomes among ART-conceived children has focused attention on the early stages of embryonic development prior to implantation. Investigations motivated by this concern have also pointed to the importance of epigenetic mechanisms in preimplantation development (PID). Likewise, research directed at the elaboration of epigenetic mechanisms and possible sources of negative ART outcomes have both pointed to the critical importance of the periconceptual environment(s) in developmental outcomes.

My intent in this chapter is to survey the current state of knowledge of cytoplasmic inheritance. Because what is known about this phenomenon (which is still very little) is enormously complex, I will need both to be selective and to engage in a certain degree of simplification, but hopefully not in a manner that distorts. Part of the elaboration of cytoplasmic inheritance involves a review of some known and conjectured developmental problems associated with ART. My purpose in discussing ART is in no way to pass judgment on the safety of ART procedures or to offer any recommendations regarding their improvement (which I am in no position to do). Rather, I discuss ART because of the insight it provides into PID, i.e., the period prior to the implantation of the blastocyst in the uterus. PID encompasses the period of cytoplasmic regulation of development and the complete activation (by cytoplasmic elements) of the embryonic genome.

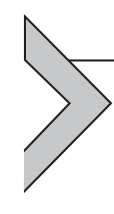

\section{OOCYTE TO IMPLANTATION (A FEW BASICS)}

At the 12-14th week of development, selected immature female germ cells called oogonia begin the first of the two meiotic divisions that will ultimately result in reducing the number of oocyte chromosomes by half. Meiosis I is arrested in the diplotene stage of prophase I, the period when the chromosomes condense along the center of the cell's nucleus in preparation for division. Shortly before birth, all the fetal oocytes in the female ovary have attained this stage and are referred to as primary oocytes. A primary oocyte, together with a surrounding layer of flat epithelial cells, is known as a primordial follicle. Oocyte maturation inhibitor, secreted by the follicular cells, will keep the primary oocytes in a dormant state for $\sim 12$ years or $\sim 1$ year 
prior to the onset of ovulation (Tsafriri \& Pomerantz, 1986). Prior to the onset of ovulation, the oocyte is reactivated and experiences a dramatic increase in size concomitant with renewed genomic transcription. Beginning at puberty, periodic hormone secretions induce a few primary oocytes to complete meiosis I, resulting in a small, nonfunctional polar body and a much larger secondary oocyte where most of the cytoplasm from the primary oocyte is concentrated. The secondary oocyte completes growth in the ovary and begins meiosis II, which is again arrested. At ovulation, the mature follicle containing the secondary oocyte ruptures releasing the oocyte. Fertilization triggers the completion of meiosis II with another asymmetric division of the oocyte resulting in the formation of a second polar body.

Fertilization occurs when the head of a single spermatozoon penetrates the zona pellucida, the hard outer membrane of the ovum, and enters the cytoplasm of the oocyte. Shortly after fertilization, the maternal and paternal chromosomes are enclosed in separate nucleic membranes forming a pair of pronuclei. Within 12-18 h postfertilization, the DNA in both the maternal and paternal pronuclei replicate as the two pronuclei approach. Upon contact, the nucleic membranes of both pronuclei dissolve leading to karyogamy, the fusion of the oocyte and sperm haploid nuclei and the formation of a diploid nucleus (i.e., a nucleus containing two sets of chromosomes, one from each parent). Approximately $30 \mathrm{~h}$ postfertilization, the first mitotic cell division, or cleavage, occurs, resulting in two cells or blastomeres. After the two-cell stage, the zygote undergoes a series of mitotic divisions without any increase in overall size (i.e., the number of cells increases but the cells become smaller with each cleavage division). Prior to the eightcell stage, these cells form a loosely arranged clump. At the eight-cell stage, the embryo undergoes a process of compaction in which the individual blastomeres maximize contact, forming a compact ball of cells. Approximately 4 days after fertilization, the compacted embryo forms a 16-cell morula, with the inner cells constituting the inner, and the surrounding cells, the outer cell mass. The inner cell mass (ICM) gives rise to the tissues of the embryo proper, while the outer cell mass forms the trophoblast, that later contributes to the placenta. About the time the morula enters the uterine cavity, fluid begins to penetrate through the zona pellucida into the intercellular spaces of the ICM. With the proliferation of fluid in the morula, the intercellular spaces become confluent and the blastocyst cavity is formed. At days 5-6, the cells of the ICM, now called the embryoblast, move to one pole, and those of the outer cell mass, or trophoblast, flatten and form the epithelial wall. At this stage, the embryo is referred to as a 
blastocyst. Approximately 1 week after fertilization, the zona pellucida disappears allowing implantation of the blastocyst in the uterine wall to begin.

\section{MATERNAL EFFECT GENES}

Human protein-coding genes typically contain several DNA sequences that code for amino acids, the building blocks of proteins, known as exons, interspersed with several introns, noncoding regions. In gene transcription, the introns and exons are first copied to create pre-messenger RNA (pre-mRNA). Pre-mRNA is then assembled to create messenger RNA (mRNA), but the path from pre-mRNA to mRNA to protein is not direct. Alternative splicing is a process in which certain exons are removed or included to produce different mRNA transcripts from the same genomic locus (Chen \& Manley, 2009). More than 98\% of multiexonic pre-mRNAs are alternatively spliced (Wang, Sandberg, et al., 2008). The distinct proteins produced from alternatively spliced identical pre-mRNAs, called isoforms, can have different, even antagonistic activities. Thus, alternative splicing plays a major role in the activity of a wide range of critical cellular processes, and during mammalian embryogenesis, it is a key to generating a viable organism from a single cell (Revil, Gaffney, Dias, Majewski, \& Jerome-Majewska, 2010). The process whereby the resulting mRNA is used to form a specific protein is called translation.

After the second meiotic arrest, oocyte gene transcription essentially stops and after fertilization, both the maternal and paternal pronuclei are largely transcriptionally silent, as is the zygotic genome after karyogamy (Wong et al., 2010). Transcription does not commence in the embryo until the activation of the embryonic genome, i.e., EGA. While EGA is not an event that occurs at one specific point in zygotic development, but rather in a series of phases or waves, analysis of patterns of de novo embryonic genome transcription indicates a major wave of genome activation at embryonic day 3 (E3), or at approximately the eight-cell stage. However, while genomic transcription is stopped pre-EGA, the translation of oocyte mRNA to synthesize proteins is not.

The oocyte contains a vast array of mRNAs, corresponding to $20-45 \%$ of the entire mouse genome (Evsikov et al., 2006; Wang et al., 2004) and their translation, along with the activity of oocyte organelles such as mitochondria, coordinated both temporally and spatially, enables early embryonic development prior to the complete activation of the embryonic genome (Bell, Calder, \& Watson, 2008). This coordination includes the 
timely translation as well as degradation and clearance of oocyte mRNAs. The window of activity of oocyte mRNAs must be carefully regulated inasmuch as their perdurance beyond their appropriate period of activity could interfere with EGA with potentially fatal consequences (Tadros \& Lipshitz, 2009).

This reliance on translational control as opposed to transcription is a universal property of oocytes that may allow for the oocyte genome to remain in a more plastic and undifferentiated state in the context of an otherwise highly differentiated cell (Seydoux \& Braun, 2006). In order to accomplish this unique regulatory feat, oocytes need to store and then utilize an abundance of factors (Tadros \& Lipshitz, 2009). When the oocyte emerges from the dormancy of the first meiotic arrest, it undergoes a period of intense metabolic activity resulting in the synthesis of large amounts of mRNAs, proteins, and macromolecular structures. As opposed to somatic cells, which divide after doubling their volume, the oocyte grows $\sim 200$ - to 300-fold without dividing (Piko \& Clegg, 1982). Those mRNAs destined to play a role in embryogenesis- "maternal mRNAs"-are stored in a form that blocks them from being translated until needed.

The genes that are transcribed to produce maternal mRNAs that play a role in embryogenesis are often referred to as maternal effect genes (MEGs) (Mager, Schultz, Brunk, \& Bartolomei, 2006). This locution is potentially misleading to the extent that the ultimate effect of any given mRNA should not simply be equated with, or ascribed to, the gene from which it was transcribed.The centrality of the distinction in embryonic development (and in all physiological processes) between transcription and translation and, as we shall see, posttranslational regulatory processes, should make this clear.That said, MEGs impact embryonic development not through genetic inheritance, but through cytoplasmic inheritance of maternal effect transcripts (mRNAs) (Bell et al., 2008; Minami, Suzuki, \& Tsukamoto, 2007).

MEGs were first described in Drosophila and included genes, the transcripts of which play a critical role in the determination of body axes (Frohnhofer \& Nusslein-Volhard, 1986; Nusslein-Volhard, Lohs-Schardin, Sander, \& Cremer, 1980; Schupbach \& Wieschaus, 1986), but were not described in mammals until 2000 (Christians, Davis, Thomas, \& Benjamin, 2000). By definition, a "canonical" or "bona fide" MEG exhibits the following properties (Yurttas, Morency, \& Coonrod, 2010). First, the effect of an MEG results not from zygotic inheritance of the gene from the mother or father, but rather from inheritance of the mRNA associated with that gene via the oocyte; second, MEG-knockout (MEG null) embryos gestated by 
normal MEG (MEG positive) mothers develop normally with the following critical exception. When MEG-null female offspring of MEG-positive mothers reach reproductive maturity, they are able to ovulate normally and their eggs can be fertilized (at least according to the most stringent definition of a MEG), but the resulting embryo arrests early in development. This is because the embryo lacks the necessary cytoplasmic mRNA/protein associated with its mother's MEG. Hence, the phenotype of a MEG-null daughter of a MEG-positive mother will be sterility, while male offspring are able to reproduce normally (and can be, in effect, carriers of the MEGnull mutation). By contrast, neither male nor female zygotes of MEG-negative mothers will survive regardless of their own genotype (Marlow, 2010).

Several different mammalian MEGs have been identified that exhibit these characteristics. For example, Maternal Antigen That Embryos Require (MATER) (given this name because of its initial use as an oocyte antigen in a mouse model of autoimmune premature ovarian failure) is synthesized from the MATER or Nlrp5 gene (Tong et al., 2000). MATER-null daughters gestated by MATER-positive mothers exhibit normal oogenesis, ovulation, and fertilization. When MATER-null daughters conceive, however, the resulting embryos generally do not progress beyond the two-cell stage. Hence, the protein(s) encoded by MATER are necessary for embryogenesis prior to the activation of the embryonic genome. MATER is one of the group of maternally encoded proteins including LOPED, FILIA, and Tle6 that interact with each other to form a protein complex called the subcortical maternal complex (Li, Baibakov, \& Dean, 2008). Female mice lacking this protein complex can ovulate and their eggs can be fertilized but their embryos do not progress beyond cleavage stage development.

Besides maternally inherited mRNAs that appear to be required only during early embryogenesis, normal embryonic development requires that some mRNAs be both inherited maternally and transcribed from the embryonic genome. The cytoplasmic mRNA provides for a protein necessary prior to EGA, while the embryonic genome provides transcripts for the same protein-or isoforms of that protein-that are necessary postEGA. An example of this is the cell adhesion protein E-cadherin, coded by the CDH-1 gene (De Vries et al., 2004). Knockout CDH-1 embryos develop to the blastocyst stage but fail to implant in the uterus. Depletion of cytoplasmic E-cadherin prior to fertilization, however, results in the arrest of normal CDH-1 embryos at the two-cell stage. In other words, cytoplasmic E-cadherin is necessary for embryonic development pre-EGA, while embryonic E-cadherin is necessary for development post-EGA. 
The number of mammalian genes that have been classified as maternal effect thus far is significantly less than the number of proteins one would expect to be necessary for pre-EGA embryonic development (Yurttas et al., 2010; Zhang et al., 2009). There are potentially many reasons for this, but I will consider five. First, given how much we do not understand about embryonic development, most MEGs have been identified serendipitously, usually when studying their possible involvement in disease phenotypes with no particular relationship to embryogenesis (Tong et al., 2000). Second, the standard research technique for identifying MEGs is a gene knockout experiment or creation of a null mutant strain in mice. The anticipated phenotype for the embryo of a MEG-null mother is either early embryonic arrest or gross deformity. However, the effects may be much more subtle or only manifested later in life, and potential phenotypes of this sort are rarely investigated in the search for MEG genes (Wilkinson, Davies, \& Isles, 2007). Third, that a gene knockout gives rise to no observable phenotype can belie its importance in development due to biological robustness. Functional redundancy is one of the mechanisms responsible for biological robustness and involves either functionally redundant duplicate genes (paralogs) (Gu, Steinmetz, Gu, ScharfeDavis, \& Li, 2003) or “degeneracy”. Degeneracy refers to a situation in which structurally distinct proteins transcribed from distinct genes bear out similar or partially overlapping functions (Edelman \& Gally, 2001). Fourth, as a matter of definition, it is often stipulated that in the "strictest sense," mutations in maternal-effect genes do not affect oocyte development, maturation, ovulation, and fertilization, but solely embryonic development (Ma, Zeng, Schultz, \& Tseng, 2006). This distinction is problematic inasmuch as the mRNAs involved in embryonic development are synthesized in the oocyte. Fifth, MEGS are usually limited to genes associated with mRNAs that are transmitted in the ooplasm. But as we shall see, there are any number of MEGs associated with the maternal environment beyond the oocyte.

\section{EPIGENETICS IN THE PREIMPLANTATION EMBRYO}

Epigenetics is the study of heritable changes in gene transcribability and phenotype that occur without changes in DNA sequence (Bollati \& Baccarelli, 2010).

A number of MEGs/mRNAs that have been identified thus far play critical roles in epigenetic processes. This is not at all surprising. During mammalian embryogenesis, the maternally and paternally derived genomes must undergo 
extensive epigenetic remodeling and alteration of their gene transcription patterns to enable embryogenesis. At fertilization, the genomes of male and female gametes possess their own distinctive epigenetic markings. The ovum is unique among cell types in that it has the ability to transition from a differentiated cell fate to one of totipotency, i.e., the ability of a cell to become any differentiated cell type in the human body. To achieve totipotency, the epigenetic states of the germ cells must be reset. To achieve cellular differentiation and development, the embryonic genome must be made accessible to transcription factors in a highly regulated spatiotemporal manner.

\subsection{Histone Modification}

Within the chromosome, DNA combines with structural proteins called histones to form chromatin, a highly coiled and compact structure. Within chromatin, a repeating structure, the nucleosome, is composed of 146 base pairs of DNA wrapped around a core of eight histone proteins, that maintain the chromatin's shape and structure (Peterson \& Laniel, 2004). Five major families of histone proteins have been identified, and these are divided into two groups based upon their location in nucleosomes: histones H2A, H2B, $\mathrm{H} 3$ and $\mathrm{H} 4$ are known as core histones; histones $\mathrm{H} 1$ and $\mathrm{H} 5$ are known as linker histones. Core histones form the center of nucleosomes while linker histones bind the nucleosomes to DNA.

Histones are subject to a wide variety of posttranslational biochemical modifications including, but not limited to, lysine acetylation, lysine and arginine methylation, serine and threonine phosphorylation, lysine acetylation, lysine and arginine methylation, serine and threonine phosphorylation, and lysine ubiquitination and sumoylation (Kouzarides, 2007). These modifications occur primarily, but not exclusively, within the histone aminoterminal "tails," the ends of the amino acid chains that make up the histone protein and protrude from the surface of the nucleosome. For a gene to be transcribed, it must be physically accessible to the transcriptional machinery. Modifications to histones can change the structure of the chromatin causing it to wind more or less tightly, making the DNA more or less accessible to transcription factors.

The most widely studied form of histone modification is histone acetylation that loosens histone binding on the DNA structure allowing for a more open chromatin structure and accessibility to transcription factors and RNA. Conversely, histone deacetylation is associated with a closed chromatin structure and inaccessibility to transcription factors. Histone acetylation and deacetylation are regulated by a balance in the activity of two 
enzymes, histone acetyltransferase (HAT) and histone deacetylase (HDAC). Histone acetylation facilitated by HAT is associated with an open chromatin structure, while histone deacetylation facilitated by HDAC results in a condensed or closed chromatin structure (Wang, Zang, et al., 2008).

The synthesis of histone proteins occurs throughout PID: $\mathrm{H} 3$ and $\mathrm{H} 4$ are synthesized during the one-cell stage from maternal mRNAs while the synthesis of $\mathrm{H} 2 \mathrm{~A}, \mathrm{H} 2 \mathrm{~B}$, and $\mathrm{H} 1$ commences during the late one-cell to two-cell stage. $\mathrm{H} 3.3$ is a variant of $\mathrm{H} 3$ that correlates with an active transcriptional state, and is observed at the two-cell, four-cell, and blastocyst stages, coinciding with major waves of gene activation during PID (Velker, Michelle, Denomme, \& Mann, 2012). The modification of histone proteins on the chromatin of early embryos is very dynamic (Palini, De Stefani, Scala, Dusi, \& Bulletti, 2011). Global patterns of histone modifications and chromatin architecture change during the early stages of development (Meshorer et al., 2006). Shortly after fertilization, sperm chromatin undergoes extensive posttranslational modification. Sperm nucleosomes contain protamines in place of histones; postfertilization, the protamines are actively removed and replaced by cytoplasmic histones (Jammes, Junien, \& Chavatte-Palmer, 2011).

Genome-wide chromatin analyses suggest that specific combinations of histone marks at DNA promoters and enhancers correlate with the developmental potential and fate of cells (Rada-Iglesias et al., 2011). For example, embryonic stem (ES) cells have a different histone modification landscape than cells with more restricted fates (Hong et al., 2011). In the blastocyst, the very first differentiated cells (those with a more restricted fate) are those that comprise the trophectoderm, which gives rise to the placenta and extraembryonic structures, while cells of the ICMs are still undifferentiated. In the embryo, OCT4 and NANOG, two genes whose proteins play a critical role in establishing totipotency, are progressively silenced by histone acetylation and histone methylation. The patterns of histone modification differ in the trophectoderm and the ICM corresponding to different timetables for the loss of totipotency and different cellular fates. The importance of these modifications in early embryogenesis is highlighted by the severe abnormal phenotypes caused by experimental mutations in histone-modifying complexes (Jiang et al., 2011; Vastenhouw \& Schier, 2012).

\subsection{DNA Methylation}

DNA methylation, the addition of a methyl group to $\mathrm{CpG}$ dinucleotides (sites in the DNA molecule where a cytosine base is followed by a guanine 
base), acts as a physical barrier to transcription factors and attracts enzymes and proteins that further reduce the transcriptional accessibility of a gene. In general, to establish and maintain methylated DNA, special enzymes called DNA methyltransferases (DNMTs) that facilitate the transfer of a methyl group to DNA are indispensible. Once a sequence of DNA is marked by methylation, another set of proteins is involved in recognizing the methylated cytosines and interacting with chromatin remodelers in order to silence transcription (Bird \& Macleod, 2004). Hence, for the most part, hypermethylation is associated with gene silencing and hypomethylation with gene activity (or potential activity).

DNMTs are divided into two groups: de novo methyltransferases recognize something in the DNA that allows them to newly methylate cytosines (this group includes DNMT3a and 3b). These are expressed mainly in early embryonic development and are involved in establishing patterns of methylation involved in cell-type differentiation (Kato et al., 2007). Maintenance methyltransferases add methylation to DNA when one strand is already methylated (this group includes DNMT1). These work throughout the life of the organism to maintain preexisting and de novo methylation patterns during mitotic cellular division, enabling daughter cells of a certain tissue type to inherit the methylation status of their progenitor (Gaudet et al., 2004).

As with histone modification, during preimplantation, DNA methylation levels undergo a series of dynamic changes (Smith et al., 2012). Mature sperm and oocytes are highly methylated until fertilization, indicating little or no transcriptional activity (Smith et al., 2012). In the mouse embryo, shortly after fertilization, the paternal pronucleus is actively demethylated, i.e., enzymes facilitate and accelerate demethylation by a process that is not well understood (Abdalla, Yoshizawa, \& Hochi, 2009). The maternal pronucleus, however, appears to be protected from active demethylation by a protein associated with the maternal effect gene STELLA (Minami et al., 2007). Instead, maternal DNA is passively demethylated via a replication dependent loss: epigenetic marks are lost because they are not maintained during several rounds of DNA replication.

Prior to the blastocyst stage, the bulk of embryonic DNA has been demethylated constituting a phase of global hypomethylation corresponding to the establishment of totipotency (Smith et al., 2012). The first cellular differentiation between the trophectoderm and the ICM is accompanied by de novo DNA methylation giving rise to stable silencing of genes involved in the maintenance of pluripotency. The level of methylation in the ICM 
is higher than that in the trophectoderm, corresponding to different timetables of cellular differentiation and different cell fates. The differences in methylation between the trophectoderm and the ICM parallel the differences in histone modification, indicating that multiple epigenetic processes work in tandem to regulate gene transcription, pluripotency, and cellular differentiation.

Mouse oocytes and preimplantation embryos lack DNMT1 but express a variant of this protein called DNMT1o, an isoform of DNMT1 that arises from an oocyte-specific alternative splicing of the DNMT1 gene (Mertineit et al., 1998). DNMT1 is classified as an MEG: the mRNA derived from the gene is upregulated in the oocyte, transmitted to the embryo via the oocyte, and plays an important role in embryogenesis (Bressan et al., 2009; Kurihara et al., 2008). DNMT1o-knockout males and females gestated by DNMT1-positive mothers appear grossly normal, but whereas males are fertile, females are infertile, and their embryos die between embryonic day (E)14 and E21 (Howell et al., 2001), making DNMT1 a "bona fide" MEG.

\subsection{Imprinting}

Imprinting is an epigenetic phenomenon in which specific alleles are expressed in a parent of origin manner. In paternally imprinted genes, the paternal allele is epigenetically modified, preventing its transcription and leading to monoallelic maternal expression; in maternally imprinted genes, the maternal allele is epigenetically modified, preventing its transcription and leading to monoallelic paternal expression. In addition to allele-specific methylation, imprinting is also associated with histone modifications and noncoding RNA (ncRNA), including microRNA (miRNA) (Spahn \& Barlow, 2003). Imprinted genes appear to be controlled at differentially methylated regions (DMRs) (Swales \& Spears, 2005). A DMR that is differentially methylated in all tissues throughout development is referred to as an imprinting control region (ICR). Such ICRs are hypothesized to be key regulators of imprinting in their particular chromosomal domains (Smallwood \& Kelsey, 2012). Another type of DMR exhibits differential patterns of tissue-specific methylation during stages of somatic development.

Approximately 200 imprinted genes have been identified thus far in the mammalian genome, including more than 100 imprinted genes in mice and at least 60 in humans (Shen et al., 2012). A study of the mouse brain suggests that detailed tissue-specific analysis could lead to the discovery of many more imprinted genes. Over $\sim 1300$ protein-coding genes and putative ncRNAs 
have been identified as associated with parent-specific allelic expression in the mouse embryonic and adult brain (Gregg et al., 2010).

Imprinting is a key reason why "monoparental" mouse embryos generated by micromanipulation do not survive. Diploid reconstituted zygotes, containing either two maternal or two paternal pronuclei, display characteristic developmental abnormalities and fail to develop to term (Santos \& Dean, 2004). Gynogenetic embryos (diploid maternal) characteristically are growth restricted and fail to derive a functional placenta. In contrast, androgenetic embryos (diploid paternal) while profoundly growth retarded, display a hyperproliferation of extraembryonic tissues.

Imprints in the parental gametes are erased upon every reproductive cycle and reestablished in the immature germ cells of the developing embryo according to their fate as either male or female gametes. Beginning approximately 11.5 days postfertilization (E11.5), the primordial germ cells begin to undergo demethylation to erase the inherited parental imprints (Lucifero, Chaillet, \& Trasler, 2004). Primordial germ cell demethylation is complete by $\sim \mathrm{E} 13$, and subsequent reprogramming of the germ cells occurs when the gender-specific imprinting patterns are once more laid down (Sasaki \& Matsui, 2008).

In contrast to the erasure and reestablishment of methylation marks in germ cells, somatic imprinted genes remain methylated throughout embryogenesis. Despite alterations in global methylation levels and chromatin organization during fertilization and early development, patterns of methylation at most somatic imprinted loci in the embryo are specifically conserved during early development without any de novo reprogramming. Cytoplasmic proteins transcribed from maternal genes DNMT1 and STELLA are involved in protecting methylation at imprinted loci during genomewide preimplantation demethylation, ensuring the correct inheritance of parent-specific epigenetic imprints (Santos \& Dean, 2004).

\subsection{Noncoding RNAs}

Non-coding RNAs (ncRNAs), unlike mRNAs, are not involved in gene transcription. Instead, they function as a vast system of posttranscriptional regulation of DNA expression (Mattick, 2001). Included among ncRNAs are at least 1000 different kinds of micro RNAs (miRNAs) - and the number may be as high as 20,000 - short RNA molecules approximately 22 nucleotides long (Osman, 2012). miRNAs are derived from longer primary transcripts (pri-miRNA) by the action of at least two enzymes, Drosha and Dicer. Mature miRNAs associate with a protein complex-the RNAinduced silencing complex - that contains an Argonaute protein at its core, 
and it is in this context that they carry out their regulatory role. For the most part, RNAs are negative regulators of gene transcription, partially binding to complementary sequences in mRNA resulting in posttranscriptional repression of gene expression.

Maternally inherited miRNAs are abundant in the early embryo (Tang et al., 2007). Dynamic changes in the expression of miRNAs in preimplantation embryos and the increased synthesis of miRNAs after the two-cell stage in mouse embryos suggest that miRNAs have a functional role during this period (Laurent, 2008; Sirard, 2012). Dicer deficiency is lethal during mouse embryogenesis, leading to a lack of detectable stem cells and an acute loss of cell proliferation (Murchison et al., 2007). Similarly, the Argonaute protein Ago2 is required for development through the EGA period. Although the mechanisms of miRNA action are not well defined, it has been hypothesized that one role of miRNA is as a control mechanism in the timely degradation of maternal mRNAs (Schier, 2007). miRNAs may also play roles in cellular differentiation during the blastocyst stage. A cluster of miRNAs from miR290 to miR-295 were found to be ES cell-specific and may be associated with the maintenance of pluripotency (Shi \& Wu, 2009; Yang et al., 2008).

\subsection{X-chromosome Inactivation}

$\mathrm{X}$-chromosome inactivation (XCI) provides a good example as to how the various epigenetic mechanisms canvassed above can interact. X-chromosome activity changes dynamically in female offspring during PID due to a combination of epigenetic events including DNA methylation, histone modifications, and RNA-mediated silencing. In female embryos with two X chromosomes, one of the two $\mathrm{X}$ chromosomes is selected stochastically to be inactivated, a process known as XCI. XCI is triggered by an ncRNA, Xist, which coats the chromosome selected for silencing (Plath, Mlynarczyk-Evans, Nusinow, \& Panning, 2002). This is followed by the recruitment of protein complexes involved in multiple epigenetic processes, distinct histone modifications such as H3 K4 demethylation, H3 K9 methylation, $\mathrm{H} 4$ deacetylation, and DNA hypermethylation of CpG dinucleotides along X-linked genes (Lee, 2003).

\section{CYTOPLASMIC ORGANELLES}

\subsection{Mitochondria}

In addition to providing essential mRNAs, ncRNAs, and proteins, the oocyte also provides the primary source of cellular energy in the form of mitochondria. Mitochondria are intracellular organelles, small membrane-enclosed 
structures within the cell, in which the end product of the breakdown of glucose in cells is processed to form the primary source of cellular energy, adenosine triphosphate (ATP). While paternal sperm-derived mitochondria are present in the zygote, they are rapidly degraded upon fertilization. Hence, mitochondria are maternally inherited in mammals, and as mitochondria cannot be made de novo, but rather only elaborated from other mitochondria, all of our mitochondria ultimately derive from those in one of our mother's oocytes. In addition to being the primary source of cellular energy, mitochondria also play a central role in a number of critical cellular and metabolic processes (Dumollard, Duchen, \& Carroll, 2007) including cellular proliferation; apoptosis or programmed cell death (cellular suicide), a process aimed at destroying a physiologically unwanted cell (Desagher \& Martinou, 2000); the regulation and homeostasis of intracellular calcium, which acts as an intracellular signal involved in numerous cellular processes including cellular expression and metabolism; and DNA repair. Mitochondria also play a critical role in oogenesis, fertilization, and early embryogenesis (Dumollard et al., 2007; McBride, Neuspiel, \& Wasiak, 2006).

Mitochondria possess their own DNA-mitochondrial DNA (mtDNA)a circular double-stranded genome. mtDNA exhibits polyploidy, differences in the number of mtDNA copies according to cell type (Clay Montier, Janice, Deng, \& Bai, 2009). For example, there are 1075-2794 copies of mtDNA per cell in muscle cells, 1200-10,800 in neurons, and up to 25,000 in liver cells. But by far, the greatest copy number of mitochondria occurs in oocytes, and oocytes from the same female can differ significantly in the number of mtDNA they contain, with human oocytes from the same female containing anywhere from 11,000 to 903,000 mtDNA molecules per oocyte (May-Panloup, Chretien, Malthiery, \& Reynier, 2007).

Studies indicate that mitochondrial number, distribution, and structure play essential roles in fertilization and normal embryonic development. mtDNA copy number expands during oocyte maturation (Bentov et al., 2010) and the normality of preovulatory meiotic maturation of the oocyte has been linked to mtDNA copy number. The number of mitochondria and mtDNA in the oocyte at the time of ovulation is critical for both fertilization and ensuing embryo development. Studies indicate that the mean mtDNA copy number in human fertilized oocytes is $\sim 250,000$ (Clay Montier et al., 2009), while for unfertilized oocytes, the mean is 164,000 , and it has been suggested that a mitochondrial complement of at least $\sim 100,000$ copies of mtDNA is required for normal embryonic development (Shoubridge \& Wai, 2007). 
In all eukaryotic cells (cells containing a membrane enclosed nucleus), energy in the form of ATP is created through two pathways (Pon \& Schon, 2007; Scheffler, 2008): In one-anaerobic respiration-glucose is metabolized to pyruvate that can then be converted to lactic acid. The energy created by this mechanism does not involve oxygen (hence the term anaerobic respiration). Anaerobic respiration is inefficient due to the incomplete metabolism of glucose. The other pathway to ATP formation, aerobic respiration, requires oxygen. Aerobic respiration also involves the conversion of glucose to pyruvate, but the pyruvate enters the inner membrane of the mitochondria where it is completely metabolized to carbon dioxide and water. Because the end product of aerobic respiration is the complete breakdown of glucose to water and carbon dioxide, it is $\sim 14$ times more efficient than anaerobic respiration.

The role of aerobic respiration in human preimplantation embryo development, although clearly present, is controversial. Mitochondria within human oocytes and preblastocyst-stage embryos appear immature and relatively inactive (Bavister \& Squirrell, 2000; Motta et al., 2000). In fact, although oxygen is consumed during preimplantation embryo development (Houghton et al., 1996), estimates of the contribution of mitochondrial respiration to the energetic requirement of mammalian embryo development suggest that as little as $10 \%$ of glucose is metabolized through aerobic respiration in the early stages of development, rising to $85 \%$ in the blastocyst (Bavister \& Squirrell, 2000). However, since aerobic respiration is 14 times more efficient than anaerobic respiration, the $10 \%$ of glucose passing through aerobic respiration probably still produces more energy in the form of ATP than the $90 \%$ of total glucose metabolized without mitochondria. Overall, the data suggest that both aerobic and anaerobic respiration pathways are active during both oocyte maturation and embryo PID, but aerobic respiration is upregulated during blastocyst development and implantation (Wilding, Coppola, Dale, \& Di Matteo, 2009).

Calcium $\left(\mathrm{Ca}^{2+}\right)$ acts as an ubiquitous intracellular signal that controls various cellular processes including proliferation, transcription, metabolism, and fertilization (Islam, 2012). By taking up and releasing $\mathrm{Ca}^{2+}$ and thereby acting as a $\mathrm{Ca}^{2+}$ buffer, mitochondria play a key role in its regulation. They can activate or deactivate plasma membrane channels that are regulated by changes in $\mathrm{Ca}^{2+}$ concentrations or restrict $\mathrm{Ca}^{2+}$ signals to specific cellular domains. Upon fertilization, sperm entry in the cytoplasm triggers repetitive $\mathrm{Ca}^{2+}$ waves that traverse the egg. This sperm-triggered $\mathrm{Ca}^{2+}$ oscillation 
is crucial for the initiation of embryonic developmental events including the breakdown of the nuclear membranes of the pronuclei, mitosis, and cytokinesis (the process in which the cytoplasm is divided during cellular division) (May-Panloup et al., 2007; Wilding et al., 2009). During PID, specific and diverse $\mathrm{Ca}^{2+}$ signals occur both intra- and intercellularly, and these $\mathrm{Ca}^{2+}$ pulses and waves are involved in everything from body axis formation in the blastula to gastrulation to organogenesis (Cao \& Chen, 2009; Shoubridge \& Wai, 2007).

\subsection{Nucleoli}

Ribosomes are small organelles involved in translating the nucleotide sequence of mRNA into an amino acid sequence to produce proteins. A cell typically contains anywhere from 1000 to one million ribosomes. A ribosome is composed of $\sim 60 \%$ ribosomal RNA (rRNA) and $40 \%$ protein. The synthesis of rRNA and ribosome subunit assembly takes place within a structure in the nucleus known as the nucleolus (Olson, 2004). Nucleoli are formed around specific genetic loci called nucleolar organizing regions, composed of tandem repeats of rRNA genes found on several different chromosomes (Raska, Shaw, \& Cmarko, 2006). Since the nucleolus of spermatozoa is eliminated during spermatogenesis (Schultz \& Leblond, 1990), the embryonic nucleolus is inherited in the cytoplasm.

After the second meiotic arrest, oocyte gene transcription of rRNA stops along with all other gene transcription. After fertilization, the maternally derived, transcriptionally inactive nucleolus appears in both male and female pronuclei and in the embryonic nuclei until the four-cell or eightcell stage; that is, it is present until EGA (Zatsepina, Baly, Chebrout, \& Debey, 2003). Although the nucleolus at this stage appears to be inactive and shows a highly compacted structure, studies with mice have revealed that it is essential for early embryonic development (Ogushi et al., 2008; Ogushi \& Saitou, 2010). Embryos originating from enucleolated oocytes arrest between the two-cell and four-cell stages (Ogushi et al., 2008). Interestingly, one of the abnormalities noted is related to abnormal chromatin organization in the pronucleus.

\section{ASSISTED REPRODUCTIVE TECHNOLOGY}

The definition of artificial reproductive technology (ART) varies widely, but the US Center for Disease Control and Prevention (CDC) 
defines ART as all fertility treatments in which both egg and sperm are handled (Savage, Peek, Hofman, \& Cutfield, 2011). Procedures that may be used in the ART process include hormonal stimulation to induce ovulation, in vitro fertilization (IVF), intracytoplasmic sperm injection in which a single sperm is injected directly into the egg in an attempt to achieve fertilization, and the cryogenic freezing of embryos. ART may involve any combination of these, but the most commonly used technique employed in all procedures is IVF, the mixing of eggs with sperm in a specific culture in a Petri dish and the implantation of embryos in the woman's uterus from 1-6 days postfertilization (Glujovsky, Blake, Farquhar, \& Bardach, 2012). IVF currently accounts for more than $99 \%$ of ART procedures performed worldwide (http://www.ivf-worldwide.com/).

ART has been associated with both pregnancy complications and adverse developmental outcomes. However, studies of adverse outcomes after the use of ART have been questioned, and remain controversial, for at least two reasons. First, adverse outcomes could be due to the underlying causes of subfertility and not ART itself. Second, multiple births have been overrepresented in assisted pregnancies due to the common practice of implanting multiple IVF eggs to increase the likelihood of pregnancy. Since multiple births are themselves associated with an increased risk of negative outcomes, it has been difficult to determine whether pregnancy complications and adverse outcomes are a result of ART or owing to multiple births and their associated complications.

The practice in certain countries of limiting the number of embryos that can be transplanted to just one has resulted in a rise in the number of ART-conceived singletons. Studies of perinatal outcomes of ART singletons appear to show even stronger differences between ART and non-ART singletons compared to ART and non-ART twins (Ceelen, van Weissenbruch, Vermeiden, van Leeuwen, \& Delemarre-van de Waal, 2008; Helmerhorst, Perquin, Donker, \& Keirse, 2004; McDonald, Murphy, Beyene, \& Ohlsson, 2005). ART singletons, when compared with naturally conceived singletons, are at significantly increased risk of placental abnormalities, low birth weight, preterm birth, small for gestational age, perinatal mortality, and congenital malformations (Hansen, Bower, Milne, de Klerk, \& Kurinczuk, 2005; Jackson, Gibson, Wu, \& Croughan, 2004; McDonald, Han, Mulla, \& Beyene, 2010; Rimm et al., 2004). Preterm birth is associated with increased morbidity, mortality, and diminished long-term survival and reproduction (McIntire \& Leveno, 2008; Swamy, Ostbye, \& Skjaerven, 2008), while low birth weight is associated with chronic diseases 
expressed later in life such as cardiovascular disease, hypertension, and type 2 diabetes (Barker, 2004).

\subsection{IVF and Epigenetics}

There is a growing body of evidence that IVF (and/or other ART techniques) can result in epigenetic abnormalities in the preimplantation embryo. Concern for epigenetic effects of IVF has arisen primarily from the observation of an increased incidence of rare genomic imprinting disorders such as Beckwith-Wiedemann syndrome (BWS) and Angelman syndrome (AS) in children born after the use of IVF.

Imprinting disorders can result either from genetic mutations or from nongenetic imprinting defects known as epimutations (Moore \& Oakey, 2011). The genetic mutations associated with imprinting disorders can consist of (1) large deletions or duplications of chromosomal regions that contain imprinted genes; (2) DNA mutations in genes that are usually imprinted or in their imprinting control centers; or (3) uniparental disomy (UPD), two copies of a chromosome from the same parent. Epimutations involve an epigenetic alteration without any change in the DNA sequence and can arise as a result of errors in imprint establishment, erasure, or maintenance. If primary epimutations occur shortly after fertilization, they can be propagated to multiple tissues.

AS is a debilitating neurodevelopmental disorder that affects approximately one in 15,000 children and is characterized by motor dysfunction, severe mental retardation, speech impairment, frequent seizures, hyperactivity, and a high prevalence of autism (Williams et al., 2006). Recent studies indicate that a failure to inherit a normal maternal copy of the paternally imprinted UBE3A gene accounts for $85-90 \%$ of all AS cases. Because of a mutation in the maternal UBE3A allele or paternal UPD, offspring lack an active copy of the maternal UBE3A gene (Greer et al., 2010). Normally, the paternal UBE3A gene is paternally imprinted-hence only the maternal allele is expressed-in specific brain regions including the hippocampus, cerebellum, and regions of the neocortex, but not in nonnervous system tissues (Albrecht et al., 1997). Approximately 3\% of patients with AS have an imprinting defect or epimutation as evidenced by the presence of two "normal" copies of the UBE3A gene that are both epigenetically silenced (Greer et al., 2010).

IVF has been associated with AS as a consequence of reports of five IVF-conceived patients with epimutation AS (Cox et al., 2002; Ludwig et al., 2005; Orstavik, Eiklid, van der Hagen, Spetalen, \& Kierulf, 2003). 
The link between AS and IVF is based on the rarity of AS $(1: 15,000)$, the rarity of primary epimutations as a mechanism of AS $(\sim 3 \%)$ and the relatively infrequent use of IVF as a method of conception (2-3\%) (Amor \& Halliday, 2008).

BWS is an overgrowth syndrome that affects one in 13,700 children and is characterized by macroglossia, abnormally large abdominal organs, hypoglycemia in infancy, kidney abnormalities, and cancerous and noncancerous tumors (Weksberg, Shuman, \& Bruce Beckwith, 2009). The majority of BWS patients have an epimutation affecting the maternal allele of one of the two DMRs at chromosome 11p15. In one region, the maternal H19 imprinted domain acquires a paternal epigenotype. The resulting gain of H19 imprinting center methylation results in silencing of H19 expression and activation of insulin-like growth factor 2 (IGF2) receptor gene expression. The second imprinting defect occurs at the KCNQ10T1 domain and results from loss of methylation on the maternal KCNQ10T1 imprinting center with ensuing biallelic expression of KCNQ10T1 and silencing of KCNQ1 and CDKN1C. The remaining BWS patients have paternal UPD of chromosome $11 \mathrm{p}$ or a DNA mutation of the CDKN1C gene. Current estimates are that IVF children are approximately 514 times more likely to develop BWS than non-IVF children although the total numbers remain small due to the rarity of the disorder (Amor \& Halliday, 2008; Hiura et al., 2012).

Numerous animal studies have indicated an association between IVF and imprinting abnormalities. For example, it has been known for a number of years that cows and sheep produced through IVF display an increased frequency of large offspring syndrome (LOS), characterized by numerous abnormalities including immunological defects, increased fetal/neonatal death, increased birth weight, organomegaly, and skeletal and placental defects (Behboodi et al., 1995; Young, Sinclair, \& Wilmut, 1998).The phenotypes observed in LOS are similar to those observed in BWS and significantly, epigenetic abnormalities of the same loci involved in BWS are observed in calves and sheep with LOS: KCNQ10T1 is hypomethylated with a corresponding increase in KCNQ10T1 expression and decrease in CDKN1C expression (Hori et al., 2010); and LOS sheep also exhibit loss of imprinting for the IGF2 gene (Young et al., 2001). The similarities in IVF-induced epigenetic errors between humans and animal models, where subfertility is not a confounding issue, suggest that manipulation of the early embryo can lead to epigenetic perturbations 
with potential long-term consequences for offspring (Paolini-Giacobino, 2007; Velker et al., 2012). There is an additional concern that IVF could result in subtle abnormalities that present later in life. For example, in mice, several studies (Calle et al., 2012; Ecker et al., 2004; FernandezGonzalez et al., 2004; Watkins et al., 2007) report long-term consequences of IVF including increased incidence of obesity, elevated systolic blood pressure and heart disease, anxiety, and memory deficits.

\subsection{The Oviductal Environment}

Although the Fallopian tubes have long been considered a mere conduit for gametes and embryos, numerous studies have demonstrated that the oviduct is involved in a number of important processes that contribute to an optimal environment for fertilization and early embryonic development (Avilés, Gutiérrez-Adán, \& Coy, 2010; Lee, Cheong, Chow, Lee, \& Yeung, 2009; Tse et al., 2008). The oviductal secretion is a complex fluid formed by secreted components from epithelial cells and blood plasma, and includes growth factors, cytokines (small protein messengers involved in the immune system) and cytokine receptors, hormones and hormone receptors, proteases (enzymes involved in the breakdown of proteins) and protease inhibitors, antioxidants (substances that protect cells against the effects of free radicals produced by ATP production in mitochondria), and chaperones and heat shock proteins that are expressed in response to rises in temperature and other environmental stressors. Preimplantation embryos interact with oviductal epithelial cells to regulate the production of oviductal proteins (Tauber, Wettich, Nohlen, \& Zaneveld, 1985), including the production of specific embryotrophic factors that stimulate embryonic growth (Tse et al., 2008).

As noted earlier, there are two main pathways in ATP generation that are necessary for embryonic cellular metabolism: aerobic and anaerobic respiration. Anaerobic respiration predominates in early PID, where pyruvate and lactate are the embryo's main sources of energy, and glucose uptake is minimal. The capacity to metabolize glucose increases significantly during the transition from the morula to blastocyst stage and by the blastocyst stage, glucose has become the preferred nutrient. Significantly, the nutrients available within the human female reproductive tract mirror the changing nutrient preferences of the developing embryo (Lane \& Gardner, 2007). The oviductal fluid is characterized by relatively high concentrations of pyruvate and lactate and a relatively 
low concentration of glucose. In contrast, uterine fluid is characterized by relatively low levels of pyruvate and lactate and a higher concentration of glucose.

Available commercial IVF culture media attempt to reproduce the preimplantation environment, at least to the extent of providing the embryo with nutrients and essential marcomolecules known to be present in the oviduct (Xella et al., 2010). The majority of commercial culture systems are sequential, i.e., different cultures are used at different stages of preblastocyst development in an attempt to mimic the dynamic in vivo environment of early embryo oviductal development (Nelissen et al., 2012). There is a general consensus, however, that all culture systems are "suboptimal" in the sense that the optimal environment for early embryonic development is the oviduct and there is no way to reproduce that environment in a Petri dish. For example, Market-Velker, Fernandes, and Mann (2010) compared five human commercial media systems in a mouse model. IVF mouse embryos produced in all five culture systems displayed a varying, but compromised ability to maintain genomic imprinting in comparison with in vivo-derived mouse embryos.

There is much more to the oviductal environment than oviductal fluid. Physiologically, the preimplantation embryo develops in a hypoxic (low oxygen) environment (oxygen concentration: 5-7\%), whereas in vitro embryos are cultured with normal atmospheric oxygen tension (oxygen concentration: 20\%) (Chason, Csokmay, Segars, DeCherney, \& Randall Armant, 2011). Embryo culture at atmospheric oxygen tension has been associated with increased production of reactive oxidative species (ROS), which are byproducts of aerobic respiration that can damage cell function by modifying the structure of lipids, proteins, and DNA causing strand breaks and inactivation of enzymes (Guerin, El Mouatassim, \& Menezo, 2001; Kitagawa, Suzuki,Yoneda, \& Watanabe, 2004).

At the same time, ROS serve as key signaling molecules by acting as second messengers through the regulation of key transcription factors, and their disruption can have detrimental developmental consequences (Dennery, 2007). Studies evaluating embryonic development under physiological oxygen concentrations have noted an increase in blastocyst development and embryo cell number across multiple species, although the mechanism is unclear (Bedaiwy et al., 2010; Chason et al., 2011; Kitagawa et al., 2004; Thompson, Simpson, Pugh, Donnelly, \& Tervit, 1990; Wale \& Gardner, 2010). Furthermore, physiological oxygen tension appears to preserve pluripotency in cultured human ES cell lines, while loss of pluripotency and 
spontaneous cellular differentiation is more frequent in embryonic cells cultured under atmospheric conditions (Forristal, Wright, Hanley, Oreffo, \& Houghton, 2010).

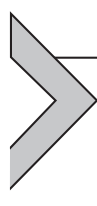

\section{CONCLUSIONS}

In conclusion, I would like to emphasize four points. First, biological inheritance is not simply a matter of the inheritance of genes. PID demonstrates, in a vivid way, that the genome does not control development in the manner traditionally conceived. This is because a critical period of embryonic development, the pre-EGA, occurs when the embryo effectively lacks a functioning genome. Cytoplasmic inheritance directs the earliest developmental processes and some of that inheritance (e.g., mitochondria and mtDNA) persists throughout the life course. Furthermore, what occurs in the fertilized ovum, although unique in many ways, highlights the importance of processes that occur in every cell. Gene transcription depends upon some combination of enzymatic and epigenetic processes. It is, therefore, necessarily both an epigenetic and epistatic process. Furthermore, transcription is a step in an extraordinarily complex, multilayered, interactive regulatory system that leads from the assembly of pre-mRNA to the assembly of a protein.

Second, PID demonstrates the centrality of epigenetic processes in human development. Embryogenesis is characterized by extensive epigenetic modifications of the oocyte, the pronuclei, and the preimplantation embryo. These epigenetic modifications enable among many other things (known and unknown), the restructuring of paternal and maternal DNA to form the pronuclei, the establishment of pluripotency through the erasure of preexisting epigenetic marks, the maintenance and reestablishment (in the germ cells) of imprinting, XCI, and cellular differentiation.

Third, the oviduct is not a mere conduit for the transmission of the embryo to the uterus. It is an environment designed to promote the early stages of embryonic development. It is also an environment with which the embryo continually communicates during the interactive process of development. Alterations in this environment can affect PID with potential long-term health consequences. The oviduct is, of course, not an environment distinct from the environment of the mother's body, nor is the mother's body an environment distinct from all the environments she occupies. There is growing evidence that all these environments can impact 
PID with potentially lifelong consequences (Ashworth, Toma, \& Hunter, 2009; Igosheva et al., 2010; Junien, 2006; Kwong, Wild, Roberts, Willis, \& Fleming, 2000).

Finally, it is worth noting that ART can be seen as a testament to the ability of the preimplantation embryo to adapt to the changes in its environment, i.e., its phenotypic plasticity. Fertilization to the preimplantation embryo represents a developmental window (one of many), but despite a common assumption that developmental windows entail "fragility," the embryo appears, for the most part, to be able to accommodate itself to a very alien environment. Epigenetic alterations seen in ART embryos may represent adaptive epigenetic responses. Phenotypic plasticity is often discussed in the context of the maternal environment: changes in that environment can transmit information to offspring about the environment they will inhabit. If the cues from the maternal environment (pre and postnatal) are good predictors of the environment in which offspring will find themselves, then the offspring's phenotypic adjustments are adaptive (Qvarnstrom \& Price, 2001). What is in some way unique about IVF is that to the extent that the preimplantation IVF embryo receives cues from the environment, it is not a maternal environment but rather an artificially constructed one. Nonetheless, its responses may be such as to enable it to survive, in relative health, until implantation. Yet just as with maternal effects, a high degree of phenotypic plasticity may also imply that sometimes the cues from the environment are maladaptive.

\section{REFERENCES}

Abdalla, H., Yoshizawa, Y., \& Hochi, S. (2009). Active demethylation of paternal genome in mammalian zygotes. Journal of Reproduction and Development, 55(4), 356-360.

Albrecht, U., Sutcliffe, J. S., Cattanach, B. M., Beechey, C.V., Armstrong, D., Eichele, G., et al. (1997). Imprinted expression of the murine Angelman syndrome gene, Ube3a, in hippocampal and Purkinje neurons. Nature Genetics, 17(1), 75-78.

Amor, D. J., \& Halliday, J. (2008). A review of known imprinting syndromes and their association with assisted reproduction technologies. Human Reproduction, 23(12), 2826-2834.

Amundson, R. (2005). The changing role of the embryo in evolutionary thought: Roots of evo-devo. Cambridge; New York: Cambridge University Press.

Ashworth, C. J., Toma, L. M., \& Hunter, M. G. (2009). Nutritional effects on oocyte and embryo development in mammals: implications for reproductive efficiency and environmental sustainability. Philosophical Transactions of the Royal Society of London B Biological Sciences, 364(1534), 3351-3361.

Avilés, M., Gutiérrez-Adán, A., \& Coy, P. (2010). Oviductal secretions: will they be key factors for the future ARTs? Molecular Human Reproduction, 16(12), 896-906.

Barker, D. J. (2004). The developmental origins of adult disease. Journal of the American College of Nutrition, 23(Suppl. 6). 588S-95S.

Bavister, B. D., \& Jayne, M. S. (2000). Mitochondrial distribution and function in oocytes and early embryos. Human Reproduction, 15(Suppl. 2), S189-S198. 
Bedaiwy, M. A., Mahfouz, R. Z., Goldberg, J. M., Sharma, R., Falcone, T., Abdel Hafez, M. F. et al. (2010). Relationship of reactive oxygen species levels in day 3 culture media to the outcome of in vitro fertilization/intracytoplasmic sperm injection cycles. Fertility and Sterility, 94(6), 2037-2042.

Behboodi, E., Anderson, G. B., BonDurant, R. H., Cargill, S. L., Kreuscher, B. R., Medrano, J. F., et al. (1995). Birth of large calves that developed from in vitro-derived bovine embryos. Theriogenology, 44(2), 227-232.

Bell, C. E., Calder, M. D., \& Watson, A. J. (2008). Genomic RNA profiling and the programme controlling preimplantation mammalian development. Molecular Human Reproduction, 14(12), 691-701.

Bentov, Y., Esfandiari, N., Burstein, E., \& Casper, R. F. (2010). The use of mitochondrial nutrients to improve the outcome of infertility treatment in older patients. Fertility and Sterility, 93(1), 272-275.

Bird, A., \& Macleod, D. (2004). Reading the DNA methylation signal. Cold Spring Harbor Symposia on Quantitative Biology, 69, 113-118.

Bollati, V., \& Baccarelli, A. (2010). Environmental epigenetics. Heredity, 105(1), 105-112.

Bressan, F. F., De Bem, T. H.C., Perecin, F., Lopes, F. L., Ambrosio, C. E., Meirelles, F. V., et al. (2009). Unearthing the roles of imprinted genes in the placenta. Placenta, 30(10), 823-834.

Calle, A., Fernandez-Gonzalez, R., Ramos-Ibeas, P., Laguna-Barraza, R., Perez-Cerezales, S., Bermejo-Alvarez, P., et al. (2012). Long-term and transgenerational effects of in vitro culture on mouse embryos. Theriogenology, 77(4), 785-793.

Cao, X., \& Chen,Y. (2009). Mitochondria and calcium signaling in embryonic development. Seminars in Cell and Developmental Biology, 20(3), 337-345.

Ceelen, M., van Weissenbruch, M. M.,Vermeiden, J. P., van Leeuwen, F. E., \& Delemarre-van de Waal, H.A. (2008). Growth and development of children born after in vitro fertilization. Fertility and Sterility, 90(5), 1662-1673.

Chason, R. J., Csokmay, J., Segars, J. H., DeCherney, A. H., \& Randall Armant, D. (2011). Environmental and epigenetic effects upon preimplantation embryo metabolism and development. Trends in Endocrinology and Metabolism, 22(10), 412-420.

Chen, M., \& Manley, J. L. (2009). Mechanisms of alternative splicing regulation: insights from molecular and genomics approaches. Nature Reviews Molecular Cell Biology, 10(11), $741-754$

Christians, E., Davis, A. A., Thomas, S. D., \& Benjamin, I. J. (2000). Maternal effect of Hsf1 on reproductive success. Nature, 407(6805), 693-694.

Clay Montier, L. L., Deng, Janice J., \& Bai,Y. (2009). Number matters: control of mammalian mitochondrial DNA copy number. Journal of Genetics and Genomics, 36(3), 125-131.

Cox, G. F., Burger, J., Lip,V., Mau, U. A., Sperling, K., Wu, B. L., et al. (2002). Intracytoplasmic sperm injection may increase the risk of imprinting defects. American Journal of Human Genetics, 71(1), 162-164.

De Vries, W. N., Evsikov, A. V., Haac, B. E., Fancher, K. S., Holbrook, A. E., Kemler, R., et al. (2004). Maternal beta-catenin and E-cadherin in mouse development. Development, 131(18), 4435-4445.

Dennery, P. A. (2007). Effects of oxidative stress on embryonic development. Birth Defects Research Part C: Embryo Today: Reviews, 81(3), 155-162.

Desagher, S., \& Jean-Claude, M. (2000). Mitochondria as the central control point of apoptosis. Trends in Cell Biology, 10(9), 369-377.

Dumollard, R., Duchen, M., \& Carroll, J. (2007). The role of mitochondrial function in the oocyte and embryo. Current Topics in Developmental Biology, 77, 21-49.

Ecker, D. J., Stein, P., Xu, Z., Williams, C. J., Kopf, G. S., Bilker, W. B., et al. (2004). Longterm effects of culture of preimplantation mouse embryos on behavior. Proceedings of the National Academy of Sciences of the United States of America, 101(6), 1595-1600. 
Edelman, G. M., \& Gally, J. A. (2001). Degeneracy and complexity in biological systems. Proceedings of the National Academy of Sciences, 98(24), 13763-13768.

Evsikov, A.V., Graber, J. H., Michael Brockman, J., Hampl, A., Holbrook, A. E., Singh, P., et al. (2006). Cracking the egg: molecular dynamics and evolutionary aspects of the transition from the fully grown oocyte to embryo. Genes and Development, 20(19), 2713-2727.

Fernandez-Gonzalez, R., Moreira, P., Bilbao, A., Jimenez, A., Perez-Crespo, M., Ramirez, M. A., et al. (2004). Long-term effect of in vitro culture of mouse embryos with serum on mRNA expression of imprinting genes, development, and behavior. Proceedings of the National Academy of Sciences of the United States of America, 101(16), 5880-5885.

Forristal, C. E., Wright, K. L., Hanley, N.A., Oreffo, R. O., \& Houghton, F. D. (2010). Hypoxia inducible factors regulate pluripotency and proliferation in human embryonic stem cells cultured at reduced oxygen tensions. Reproduction, 139(1), 85-97.

Frohnhofer, H. G., \& Nusslein-Volhard, C. (1986). Organization of anterior pattern in the Drosophila embryo by the maternal gene bicoid. Nature, 324(6093), 120-125.

Gaudet, F., M Rideout, W., Meissner, A., Dausman, J., Leonhardt, H., \& Jaenisch, R. (2004). Dnmt1 expression in pre- and postimplantation embryogenesis and the maintenance of IAP silencing. Molecular and Cellular Biology, 24, 1640.

Gilbert, S. F. (1998). Bearing crosses: a historiography of genetics and embryology. American Journal of Medical Genetics, 76(2), 168-182.

Glujovsky, D., Blake, D., Farquhar, C., \& Bardach, A. (2012). Cleavage stage versus blastocyst stage embryo transfer in assisted reproductive technology. Cochrane Database of Systematic Reviews, 11(7).

Greer, P. L., Hanayama, R., Bloodgood, B. L., Mardinly, A. R., Lipton, D. M., Flavell, S. W., et al. (2010). The Angelman syndrome protein Ube3A regulates synapse development by ubiquitinating arc. Cell, 140(5), 704-716.

Gregg, C., Zhang, J., Weissbourd, B., Luo, S., Schroth, G. P., Haig, D., et al. (2010). Highresolution analysis of parent-of-origin allelic expression in the mouse brain. Science, 329(5992), 643-648.

Gu, Z., Steinmetz, L. M., Gu, X., Scharfe, C., Davis, R. W., \& Li, W.-H. (2003). Role of duplicate genes in genetic robustness against null mutations. Nature, 421(6918), 63-66.

Guerin, P., El Mouatassim, S., \& Menezo, Y. (2001). Oxidative stress and protection against reactive oxygen species in the pre-implantation embryo and its surroundings. Human Reproduction Update, 7(2), 175-189.

Hansen, M., Bower, C., Milne, E., de Klerk, N., \& Kurinczuk, J. J. (2005). Assisted reproductive technologies and the risk of birth defects-a systematic review. Human Reproduction, 20(2), 328-338.

Helmerhorst, F. M., Perquin, D. A., Donker, D., \& Keirse, M. J. (2004). Perinatal outcome of singletons and twins after assisted conception: a systematic review of controlled studies. BMJ, 328(7434), 23.

Hiura, H., Okae, H., Miyauchi, N., Sato, F, Sato, A., Van De Pette, M., et al. (2012). Characterization of DNA methylation errors in patients with imprinting disorders conceived by assisted reproduction technologies. Human Reproduction, 27(8), 2541-2548.

Hong, S.-H., Rampalli, S., Lee, J. B., McNicol, J., Collins, T., Draper, J. S., et al. (2011). Cell fate potential of human pluripotent stem cells is encoded by histone modifications. Cell Stem Cell, 9(1), 24-36.

Hori, N., Nagai, M., Hirayama, M., Hirai, T., Matsuda, K., Hayashi, M., et al. (2010). Aberrant $\mathrm{CpG}$ methylation of the imprinting control region KvDMR 1 detected in assisted reproductive technology-produced calves and pathogenesis of large offspring syndrome. Animal Reproduction Science, 122(3-4), 303-312.

Houghton, F. D., Thompson, J. G., Kennedy, C. J., \& Leese, H. J. (1996). Oxygen consumption and energy metabolism of the early mouse embryo. Molecular Reproduction and Development, 44(4), 476-485. 
Howell, C.Y., Bestor, T. H., Ding, F., Latham, K. E., Mertineit, C., Trasler, J. M., et al. (2001). Genomic imprinting disrupted by a maternal effect mutation in the Dnmt1 gene. Cell, 104(6), 829-838. (cited) http://www.ivf-worldwide.com/.

Igosheva, N., Abramov, A. Y., Poston, L., Eckert, J. J., Fleming, T. P., Duchen, M. R., et al. (2010). Maternal diet-induced obesity alters mitochondrial activity and redox status in mouse oocytes and zygotes. PLoS One, 5(4).

Islam, S. M. (2012). Calcium signalling. (Vol. 740). Dordrecht: Springer.

Jackson, R.A., Gibson, K.A., Wu,Y.W., \& Croughan, M. S. (2004). Perinatal outcomes in singletons following in vitro fertilization: a meta-analysis. Obstetrics and Gynecology, 103(3), $551-563$.

Jammes, H., Junien, C., \& Chavatte-Palmer, P. (2011). Epigenetic control of development and expression of quantitative traits. Reproduction Fertility and Development, 23(1), 64-74.

Jiang, H., Shukla, A., Wang, X., Chen, W.-yi, Bernstein, B. E., \& Roeder, R. G. (2011). Role for Dpy-30 in ES cell-fate specification by regulation of H3K4 methylation within bivalent domains. Cell, 144(4), 513-525.

Junien, C. (2006). Impact of diets and nutrients/drugs on early epigenetic programming. Journal of Inherited Metabolic Disease, 29(2), 359-365.

Kato, Y., Kaneda, M., Hata, K., Kumaki, K., Hisano, M., \& Kohara, Y. (2007). Role of the Dnmt3 family in de novo methylation of imprinted and repetitive sequences during male germ cell development in the mouse. Human Molecular Genetics, 16, 2272-2280.

Kitagawa, Y., Suzuki, K., Yoneda, A., \& Watanabe, T. (2004). Effects of oxygen concentration and antioxidants on the in vitro developmental ability, production of reactive oxygen species (ROS), and DNA fragmentation in porcine embryos. Theriogenology, 62(7), 1186-1197.

Kouzarides, T. (2007). Chromatin modifications and their function. Cell, 128(4), 693-705.

Kurihara,Y., Kawamura,Y., Uchijima,Y.,Amamo, T., Kobayashi, H., Asano, T., et al. (2008). Maintenance of genomic methylation patterns during preimplantation development requires the somatic form of DNA methyltransferase 1. Developmental Biology, 313(1), 335-346.

Kwong, W. Y., Wild, A. E., Roberts, P., Willis, A. C., \& Fleming, T. P. (2000). Maternal undernutrition during the preimplantation period of rat development causes blastocyst abnormalities and programming of postnatal hypertension. Development, 127(19), 4195-4202.

Lane, M., \& Gardner, D. K. (2007). Embryo culture medium: which is the best? Best Practice E Research Clinical Obstetrics and Gynaecology, 21(1), 83-100.

Laurent, L. C. (2008). MicroRNAs in embryonic stem cells and early embryonic development. Journal of Cellular and Molecular Medicine, 12(6A), 2181-2188.

Lee, J. T. (2003). Functional intergenic transcription: a case study of the X-inactivation centre. Philosophical Transactions of the Royal Society of London B Biological Sciences, 358(1436), 1417-1423.

Lee, Y. L., Cheong, A. W., Chow, W. N., Lee, K. F., \& Yeung, W. S. (2009). Regulation of complement-3 protein expression in human and mouse oviducts. Molecular Reproduction and Development, 76(3), 301-308.

Li, L., Baibakov, B., \& Dean, J. (2008). A subcortical maternal complex essential for preimplantation mouse embryogenesis. Developmental Cell, 15(3), 416-425.

Lucifero, D., Chaillet, J. R., \& Trasler, J. M. (2004). Potential significance of genomic imprinting defects for reproduction and assisted reproductive technology. Human Reproduction Update, 10(1), 3-18.

Ludwig, M., Katalinic, A., Groß, S., Sutcliffe,A.,Varon, R., \& Horsthemke, B. (2005). Increased prevalence of imprinting defects in patients with Angelman syndrome born to subfertile couples. Journal of Medical Genetics, 42(4), 289-291.

Mager, J., Schultz, R. M., Brunk, B. P., \& Bartolomei, M. S. (2006). Identification of candidate maternal-effect genes through comparison of multiple microarray data sets. Mammalian Genome, 17(9), 941-949. 
Market-Velker, B. A., Fernandes, A. D., \& Mann, M. R. (2010). Side-by-side comparison of five commercial media systems in a mouse model: suboptimal in vitro culture interferes with imprint maintenance. Biology of Reproduction, 83(6), 938-950.

Marlow, F. L. (2010). In D. Kessler (Ed.), Maternal control of development in vertebrates: My mother made me do it. : Morgan \& Claypool Life Science.

Mattick, J. S. (2001). Non-coding RNAs: the architects of eukaryotic complexity. EMBO Reports, 2(11), 986-991.

May-Panloup, P., Chretien, M.-F., Malthiery,Y., \& Reynier, P. (2007). Mitochondrial DNA in the Oocyte and the Developing Embryo. In C. S. J. Justin (Ed.), Current topics in developmental biology: Academic Press.

Ma, J., Zeng, F., Schultz, R. M., \& Tseng, H. (2006). Basonuclin: a novel mammalian maternal-effect gene. Development, 133(10), 2053-2062.

McBride, H. M., Neuspiel, M., \& Wasiak, S. (2006). Mitochondria: more than just a powerhouse. Current Biology, 16(14). R551-R60.

McDonald, S. D., Han, Z., Mulla, S., \& Beyene, J. (2010). Overweight and obesity in mothers and risk of preterm birth and low birth weight infants: systematic review and metaanalyses. BMJ, 20(341).

McDonald, S. D., Murphy, K., Beyene, J., \& Ohlsson, A. (2005). "Perinatal outcomes of singleton pregnancies achieved by in vitro fertilization: a systematic review and metaanalysis". Journal of Obstetrics and Gynaecology Canada, 27(5), 449-459.

McIntire, D. D., \& Leveno, K. J. (2008). Neonatal mortality and morbidity rates in late preterm births compared with births at term. Obstetrics and Gynecology, 111(1), 35-41.

Mertineit, C., Yoder, J. A., Taketo, T., Laird, D. W., Trasler, J. M., \& Bestor, T. H. (1998). Sexspecific exons control DNA methyltransferase in mammalian germ cells. Development, 125(5), 889-897.

Meshorer, E., Yellajoshula, D., George, E., Scambler, P. J., Brown, D. T., \& Misteli, T. (2006). Hyperdynamic plasticity of chromatin proteins in pluripotent embryonic stem cells. Developmental Cell, 10(1), 105-116.

Minami, N., Suzuki,T., \& Tsukamoto, S. (2007). Zygotic gene activation and maternal factors in mammals. Journal of Reproduction and Development, 53(4), 707-715.

Moore, G., \& Oakey, R. (2011). The role of imprinted genes in humans. Genome Biology, 12(3), 106.

Motta, P. M., Nottola, S. A., Makabe, S., \& Heyn, R. (2000). Mitochondrial morphology in human fetal and adult female germ cells. Human Reproduction, 15(Suppl. 2), S129-S147.

Murchison, E. P., Stein, P., Xuan, Z., Pan, H., Zhang, M. Q., Schultz, R. M., et al. (2007). Critical roles for Dicer in the female germline. Genes and Development, 21(6), 682-693.

Nelissen, E. C., Van Montfoort, A. P., Coonen, E., Derhaag, J. G., Geraedts, J. P., Smits, L. J., et al. (2012). Further evidence that culture media affect perinatal outcome: findings after transfer of fresh and cryopreserved embryos. Human Reproduction, 27(7), 1966-1976.

Nusslein-Volhard, C., Lohs-Schardin, M., Sander, K., \& Cremer, C. (1980). A dorso-ventral shift of embryonic primordia in a new maternal-effect mutant of Drosophila. Nature, 283(5746), 474-476.

Ogushi, S., \& Saitou, M. (2010). The nucleolus in the mouse oocyte is required for the early step of both female and male pronucleus organization. Journal of Reproduction and Development, 56(5), 495-501.

Ogushi, S., Palmieri, C., Fulka, H., Saitou, M., Miyano, T., \& Fulka, J.,Jr. (2008).The maternal nucleolus is essential for early embryonic development in mammals. Science, 319(5863), 613-616.

Olson, M. O. J. (2004). The nucleolus. New York: Landes Bioscience/Kluwer Academic.

Orstavik, K. H., Eiklid, K., van der Hagen, C. B., Spetalen, S., \& Kierulf, K. (2003). Another case of imprinting defect in a girl with Angelman syndrome who was conceived by intracytoplasmic semen injection. American Journal of Human Genetics, 72, 218. 
Osman, A. (2012). MicroRNAs in health and disease-basic science and clinical applications. Clinica y Laboratoria, 58(5-6), 393-402.

Palini, S., De Stefani, S., Scala,V., Dusi, L., \& Bulletti, C. (2011). Epigenetic regulatory mechanisms during preimplantation embryo development. Annals of the New York Academy of Sciences, 1221(1), 54-60.

Paolini-Giacobino, A. (2007). Epigenetics in reproductive medicine. Pediatric Research, 61 (5, Part 2)10.1203/pdr.0b013e318039d978. 51R-7R.

Peterson, C. L., \& Laniel, M. A. (2004). Histones and histone modifications. Current Biology, 14. R546-R51.

Piko, L., \& Clegg, K. B. (1982). Quantitative changes in total RNA, total poly(A), and ribosomes in early mouse embryos. Developmental Biology, 89(2), 362-378.

Plath, K., Mlynarczyk-Evans, S., Nusinow, D. A., \& Panning, B. (2002). Xist RNA and the mechanism of X chromosome inactivation. Annual Review of Genetics, 36, 233-278.

Pon, L. A., \& Schon, E. A. (2007). Mitochondria. : Amsterdam Academic Press.

Qvarnstrom, A., \& Price, T. D. (2001). Maternal effects, paternal effects and sexual selection. Trends in Ecology and Evolution, 16(2), 95-100.

Rada-Iglesias, A., Bajpai, R., Swigut, T., Brugmann, S. A., Flynn, R. A., \& Wysocka, J. (2011). A unique chromatin signature uncovers early developmental enhancers in humans. Nature, 470(7333), 279-283.

Raska, I., Shaw, P. J., \& Cmarko, D. (2006). New insights into nucleolar architecture and activity. International Review of Cytology, 255, 177-235.

Revil, T., Gaffney, D., Dias, C., Majewski, J., \& Jerome-Majewska, L. A. (2010). Alternative splicing is frequent during early embryonic development in mouse. BMC Genomics, 11(1), 1-17.

Rimm, A. A., Katayama, A. C., Diaz, M., \& Katayama, K. P. (2004). A meta-analysis of controlled studies comparing major malformation rates in IVF and ICSI infants with naturally conceived children. Journal of Assisted Reproduction and Genetics, 21(12), 437-443.

Santos, F., \& Dean, W. (2004). Epigenetic reprogramming during early development in mammals. Reproduction, 127(6), 643-651.

Sasaki, H., \& Matsui, Y. (2008). Epigenetic events in mammalian germ-cell development: reprogramming and beyond. Nature Reviews Genetics, 9(2), 129-140.

Savage, T., Peek, J., Hofman, P. L., \& Cutfield, W. S. (2011). Childhood outcomes of assisted reproductive technology. Human Reproduction, 26(9), 2392-2400.

Seydoux, G., \& Braun, R. E. (2006). Pathway to totipotency: lessons from germ cells. Cell, 127(5), 891-904.

Scheffler, I. E. (2008). Mitochondria. Hoboken, N.J: Wiley-Liss.

Schier, A. F. (2007). The maternal-zygotic transition: death and birth of RNAs. Science, 316(5823), 406-407.

Schultz, M. C., \& Leblond, C. P. (1990). Nucleolar structure and synthetic activity during meiotic prophase and spermiogenesis in the rat. American Journal of Anatomy, 189(1), 1-10.

Schupbach, T., \& Wieschaus, E. (1986). Germline autonomy of maternal-effect mutations altering the embryonic body pattern of Drosophila. Developmental Biology, 113(2), 443-448.

Shen, C.-J., Cheng, W. T. K., Wu, S.-C., Chen, H.-L., Tsai, T.-C., Yang, S.-H., et al. (2012). Differential differences in methylation status of putative imprinted genes among cloned swine genomes. PLoS One, 7(2), e32812.

Shi, L., \& Wu, J. (2009). Epigenetic regulation in mammalian preimplantation embryo development. Reproductive Biology and Endocrinology, 7(1), 59.

Shoubridge, E.A., \& Wai,T. (2007). Mitochondrial DNA and the mammalian oocyte. Current Topics in Developmental Biology, 77, 87-111.

Sirard, M. A. (2012). Factors affecting oocyte and embryo transcriptomes. Reproduction in Domestic Animals, 4, 148-155. 
Smallwood, S. A., \& Kelsey, G. (2012). De novo DNA methylation: a germ cell perspective. Trends in Genetics, 28(1), 33-42.

Smith, Z. D., Chan, M. M., Mikkelsen, T. S., Gu, H., Gnirke, A., Regev, A., et al. (2012). A unique regulatory phase of DNA methylation in the early mammalian embryo. Nature, 484(7394), 339-344.

Spahn, L., \& Barlow, D. P. (2003). An ICE pattern crystallizes. Nature Genetics, 35(1), 11-12.

Swales, A. K. E., \& Spears, N. (2005). Genomic imprinting and reproduction. Reproduction, 130(4), 389-399.

Swamy, G. K., Ostbye, T., \& Skjaerven, R. (2008). Association of preterm birth with longterm survival, reproduction, and next-generation preterm birth. JAMA, 299(12), 1429-1436.

Tadros, W., \& Lipshitz, H. D. (2009). The maternal-to-zygotic transition: a play in two acts. Development, 136(18), 3033-3042.

Tang, F., Kaneda, M., O'Carroll, D., Hajkova, P., Barton, S. C., Sun,Y.A., et al. (2007). Maternal microRNAs are essential for mouse zygotic development. Genes and Development, 21(6), 644-648.

Tauber, P. F., Wettich, W., Nohlen, M., \& Zaneveld, L. J. (1985). Diffusable proteins of the mucosa of the human cervix, uterus, and fallopian tubes: distribution and variations during the menstrual cycle. American Journal of Obstetrics and Gynecology, 151(8), 1115-1125.

Thompson, J. G., Simpson, A. C., Pugh, P. A., Donnelly, P. E., \& Tervit, H. R. (1990). Effect of oxygen concentration on in-vitro development of preimplantation sheep and cattle embryos. Journal of Reproduction and Fertility, 89(2), 573-578.

Tong, Z. B., Gold, L., Pfeifer, K. E., Dorward, H., Lee, E., Bondy, C. A., et al. (2000). Mater, a maternal effect gene required for early embryonic development in mice. Nature Genetics, 26(3), 267-268.

Tsafriri, A., \& Pomerantz, S. H. (1986). Oocyte maturation inhibitor. Clinics in Endocrinology and Metabolism, 15(1), 157-170.

Tse, P. K., Lee, Y. L., Chow, W. N., Luk, J. M., Lee, K. F., \& Yeung, W. S. (2008). Preimplantation embryos cooperate with oviductal cells to produce embryotrophic inactivated complement-3b. Endocrinology, 149(3), 1268-1276.

Vastenhouw, N. L., \& Schier,A. F. (2012). Bivalent histone modifications in early embryogenesis. Current Opinion in Cell Biology, 24(3), 374-386.

Velker, B. A., Denomme, M. M., \& Mann, M. R. (2012). Embryo culture and epigenetics. In G. D. Smith, J. Swain \& T. B. Pool (Eds.), Embryo culture: Methods and protocols.

Wale, P. L., \& Gardner, D. K. (2010). Time-lapse analysis of mouse embryo development in oxygen gradients. Reproductive BioMedicine Online, 21(3), 402-410.

Wang, Q.T., Piotrowska, K., Ciemerych, M. A., Milenkovic, L., Scott, M. P., Davis, R. W., et al. (2004). A genome-wide study of gene activity reveals developmental signaling pathways in the preimplantation mouse embryo. Developmental Cell, 6(1), 133-144.

Wang, E. T., Sandberg, R., Luo, S., Khrebtukova, I., Zhang, L., Mayr, C., et al. (2008). Alternative isoform regulation in human tissue transcriptomes. Nature, 456(7221), 470-476.

Wang, Z., Zang, C., Rosenfeld, J., Schones, D., Barski, A., Cuddapah, S., et al. (2008). Combinatorial patterns of histone acetylations and methylations in the human genome. Nature Genetics, 40, 897-903.

Watkins, A. J., Platt, D., Papenbrock, T., Wilkins, A., Eckert, J. J., Kwong, W.Y., et al. (2007). Mouse embryo culture induces changes in postnatal phenotype including raised systolic blood pressure. Proceedings of the National Academy of Sciences of the United States of America, 104(13), 5449-5454.

Weksberg, R., Shuman, C., \& Bruce Beckwith, J. (2009). Beckwith-Wiedemann syndrome. European Journal of Human Genetics.

Wilding, M., Coppola, G., Dale, B., \& Di Matteo, L. (2009). Mitochondria and human preimplantation embryo development. Reproduction, 137(4), 619-624. 
Wilkinson, L. S., Davies, W., \& Isles, A. R. (2007). Genomic imprinting effects on brain development and function. Nature Reviews Neuroscience, 8(11), 832-843.

Williams, C. A., Beaudet, A. L., Clayton-Smith, J., Knoll, J. H., Kyllerman, M., Laan, L. A., et al. (2006). Angelman syndrome 2005: updated consensus for diagnostic criteria. American Journal of Medical Genetics Part A, 140(5), 413-418.

Wong, C. C., Loewke, K. E., Bossert, N. L., Behr, B., De Jonge, C. J., Baer, T. M., et al. (2010). Non-invasive imaging of human embryos before embryonic genome activation predicts development to the blastocyst stage. Nature Biotechnology, 28(10), 1115-1121.

Xella, S., Marsella,T., Tagliasacchi, D., Giulini, S., La Marca,A., Tirelli,A., et al. (2010). Embryo quality and implantation rate in two different culture media: ISM1 versus Universal IVF Medium. Fertility and Sterility, 93(6), 1859-1863.

Yang, Y., Bai, W., Zhang, L., Yin, G., Wang, X., Wang, J., et al. (2008). Determination of microRNAs in mouse preimplantation embryos by microarray. Developmental Dynamics, 237(9), 2315-2327.

Young, L. E., Fernandes, K., McEvoy, T. G., Butterwith, S. C., Gutierrez, C. G., Carolan, C., et al. (2001). Epigenetic change in IGF2R is associated with fetal overgrowth after sheep embryo culture. Nature Genetics, 27(2), 153-154.

Young, L. E., Sinclair, K. D., \& Wilmut, I. (1998). Large offspring syndrome in cattle and sheep. Reviews of Reproduction, 3(3), 155-163.

Yurttas, P., Morency, E., \& Coonrod, S. A. (2010). Use of proteomics to identify highly abundant maternal factors that drive the egg-to-embryo transition. Reproduction, 139(5), 809-823.

Zatsepina, O., Baly, C., Chebrout, M., \& Debey, P. (2003). The step-wise assembly of a functional nucleolus in preimplantation mouse embryos involves the cajal (coiled) body. Developmental Biology, 253(1), 66-83.

Zhang, P., Ni, X., Guo, Y., Guo, X., Wang, Y., Zhou, Z., et al. (2009). Proteomic-based identification of maternal proteins in mature mouse oocytes. BMC Genomics, 10(1), 348. 